\title{
Influence of modern immunobiological preparations based on live bacteria in compound feeds on fish-biological and physiological-biochemical parameters of sturgeon
}

\author{
Adelya Zhandalgarova ${ }^{1, *}$ Anna Bakhareva ${ }^{1}$, Yulia Grozesku ${ }^{1}$, Yulia Sergeyeva ${ }^{1}$, and Vera \\ Yegorova $^{1}$ \\ ${ }^{1}$ Astrakhan State Technical University, 414056, st. Tatishcheva, 16, Astrakhan, Russia
}

\begin{abstract}
The efficiency of modern aquaculture largely depends on the properties of the feed used. High-quality compound feed should be used by the body to the maximum extent, stimulate its growth and development, and contribute to the environmental safety of the food products produced. To obtain additional gains in body weight, increase the digestibility and assimilability of feed, stimulate nonspecific immunity and save feed costs, immunobiological preparations based on live bacteria are currently introduced into the composition of feed for animals, including fish. One of the most promising immunobiological preparations based on live bacteria is the probiotic "Ferm-KM" containing phyto-microsorbent particles, live bacillus cells and metabolites: strains Bacillus subtillis, Bacillus licheniformis, complex of lactic acid bacteria and products of their metabolism. The article presents the results of the use of the probiotic "Ferm-KM" in the composition of the production compound feed for sturgeon fish. It was found that when two-year-old Russian sturgeon are grown on a production compound feed with the addition of a probiotic, the fish-breeding and biological parameters of fish increase and the physiological and biochemical parameters of blood improve. The optimal rate of introducing probiotic into the composition of the production compound feed for commercial growing of sturgeon fish is $5 \mathrm{~g} / \mathrm{kg}$ of compound feed. The effectiveness of introducing a probiotic preparation "Ferm-KM" with an immunomodulatory effect into the composition of compound feed for sturgeon fish has been proved, which helps to increase the linear-weight gain of fish and improve blood parameters."
\end{abstract}

\section{Introduction}

Modern aquaculture is characterized by new approaches to keeping fish in dense planting conditions associated with the restoration of the natural ecology of the body and

* Corresponding author: zhandalgarova@mail.ru 
based on the use of biologically active products [1-4]. One of the aspects of this approach is the normalization of the altered microbial landscape of the body in the aquatic environment of closed water supply installations with the help of immunobiological preparations based on live bacteria, designed to correct the intestinal microflora, prevent and treat various diseases associated with a violation of the constancy of the internal environment of the body [5-8 ].

In the body of fish, there are significant deviations in autoflora caused by such phenomena as violation of conditions of keeping and feeding, constant stress effects of various etiologies, contributing to negative shifts in microflora [1]. Against the background of a deficiency of normal flora, the normal relations between obligate intestinal microorganisms are disrupted, causing an imbalance between normo- and opportunistic microorganisms and dysbacteriosis [9-15]. In this regard, the implementation of preventive measures, including the use of immunobiological drugs in order to form normobiosis and colonization resistance, is of no small importance. The introduction of these drugs into compound feed for fish contributes to the stimulation of nonspecific immunity, the treatment and prevention of infections of the gastrointestinal tract arising from a sharp change in the composition of the diet, violations of feeding regimes and technological stresses, restoration of the microbiocenosis of the digestive tract after antibiotic treatment, improvement of digestion processes, acceleration adaptation of fish to diets with high energy value and non-protein nitrogenous substances.

In modern aquaculture, immunobiological preparations based on live bacteria are used to increase weight gain, enhance natural resistance, prevent diseases and form normal microflora of the intestines of fish at all stages of development [1]. Such preparations allow to mitigate the stresses caused by the change of feed and technological effects on the fish organism, serve to increase the body's resistance and immunity tension, and make it possible to increase the digestibility of compound feed.

In this regard, the purpose of this work was to assess the effect of the immunobiological preparation "Ferm-KM" in compound feeds on the fish-biological and physiologicalbiochemical parameters of sturgeons.

\section{Material and research methods}

The experimental work was carried out in the cage complex of the KFKh Polyakova Yu.S. within 150 days (Fig. 1). Two-year-old Russian sturgeon were used as research objects (Acipenser gueldenstaedtii Brandt, 1833) (fig. 2). 


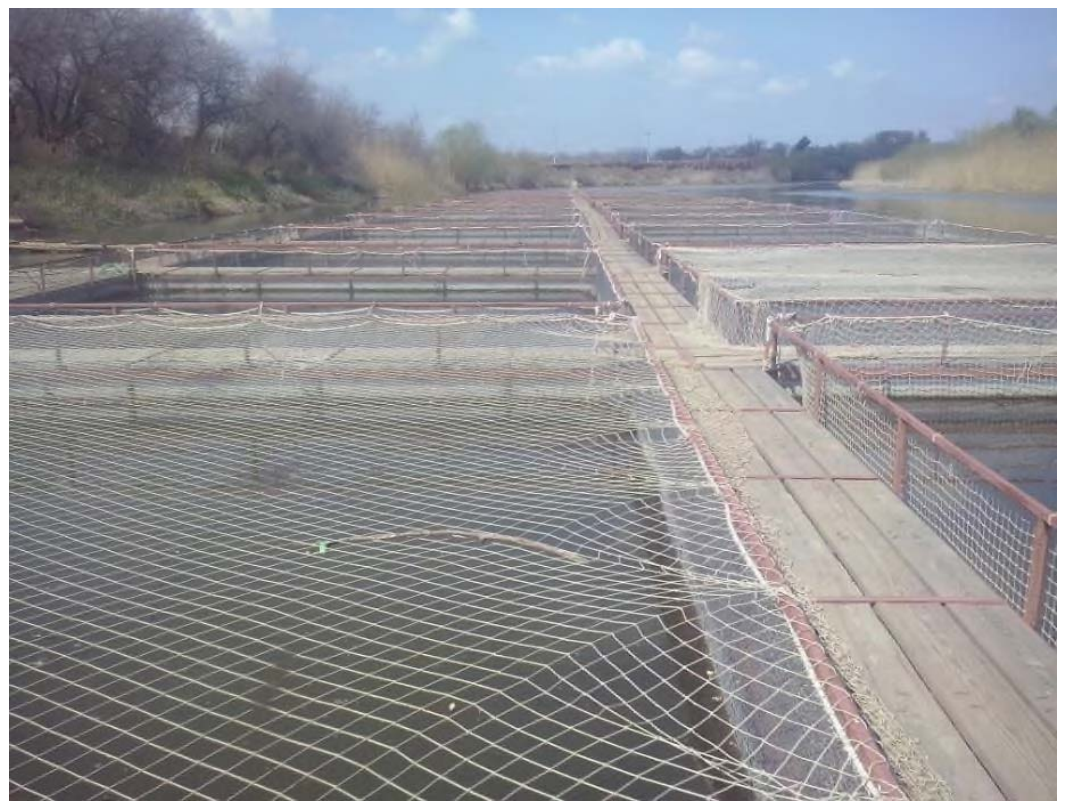

Fig. 1. Cage complex KFH Polyakov Yu.S.

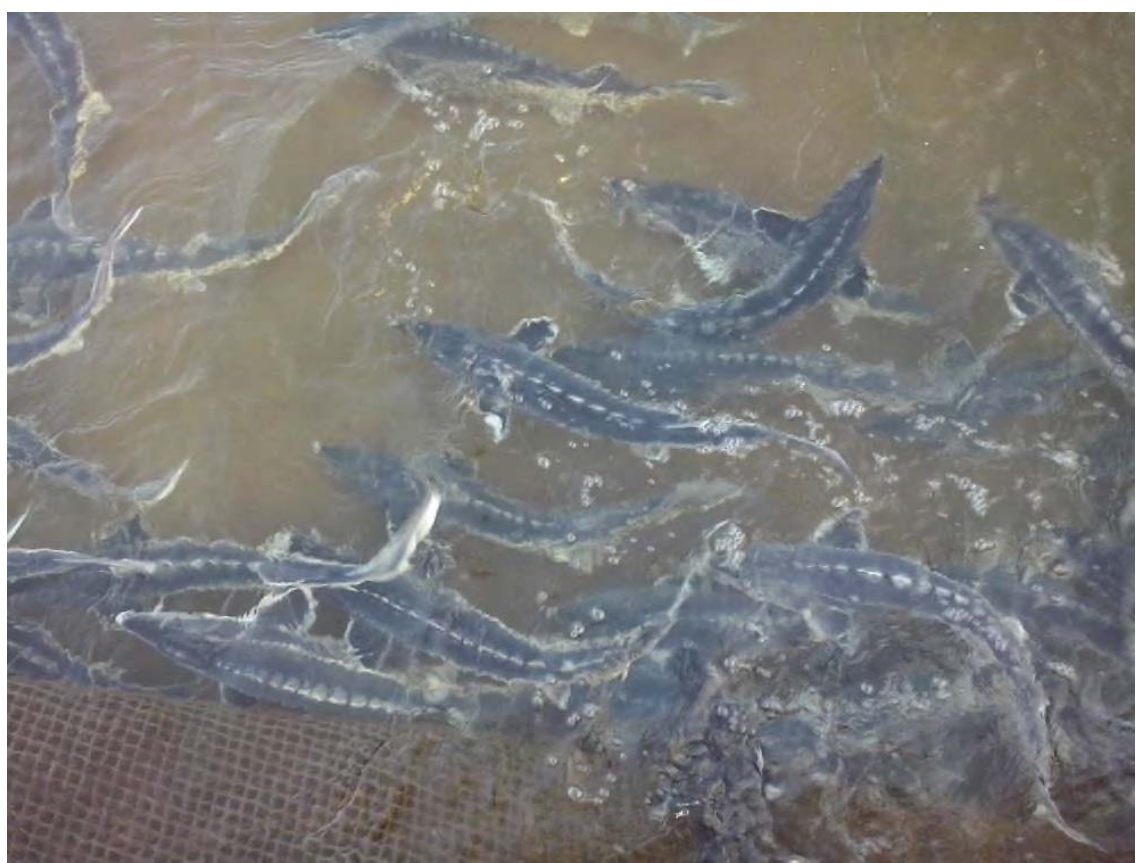

Fig. 2. Two-year-old Russian sturgeon (Acipenser gueldenstaedtii Brandt, 1833)

Experimental compound feeds were made in laboratory conditions by wet pressing using domestic feed components (Table 1). The dry form of the probiotic preparation "Ferm-KM" was introduced into the compound feed during the manufacturing process. The rate of addition of probiotic to the production compound feed for sturgeon fish is $5 \mathrm{~g} / \mathrm{kg}$ of compound feed.

Table 1. Composition of compound feed OT-7 


\begin{tabular}{|c|c|}
\hline Component & Content \\
\hline Fish flour & 39,0 \\
\hline Vitazar & 20,0 \\
\hline Wheat flour & 3,0 \\
\hline Soybean meal & 10,0 \\
\hline Corn gluten & 15,0 \\
\hline Fodder yeast & 5,0 \\
\hline Fish fat & 5,0 \\
\hline Wheat flour & 3,0 \\
\hline Sunflower oil & 2,0 \\
\hline Vitamin and mineral premix & 1,0 \\
\hline
\end{tabular}

Growing of two-year-old Russian sturgeon was carried out in cages measuring $2 \times 2 \times 1$ $\mathrm{m}$. The stocking density of two-year-olds was set depending on the weight of the fish being raised. During the entire research period, observations were made of the hydrochemical and thermal regimes, the growth and development of fish.

To assess the physiological and biochemical parameters of fish, blood was taken from the tail artery using a medical syringe. The hemoglobin content was determined photometrically using KFK-3. To determine the total protein, serum was obtained, the protein in the serum was determined using an IRF-454B2M refractometer. Erythrocyte sedimentation rate (ESR) was determined according to Panchenkov's method. Weighing and measuring of fish was carried out according to the recommendations of I.F. Pravdina.

Statistical processing of the research results was carried out according to the generally accepted methods of mathematical processing using the Microsoft Excel program. The elements of statistical analysis were used to determine the average error.

\section{Research results}

Evaluation of the effectiveness of the introduction of the immunobiological preparation "Ferm-KM" into the compound feed for sturgeon fish was carried out with the division of farmed fish into two groups: control and experimental. The control group of two-year-old Russian sturgeon used compound feed of the OT-7 formulation, the experimental group compound feed of the OT-7 formulation with the addition of the probiotic "Ferm-KM". Fish-biological indicators of sturgeon rearing are presented in Table 2.

Table 2. Fish-breeding and biological indicators of sturgeon rearing

\begin{tabular}{|c|c|c|}
\hline \multirow{2}{*}{ Index } & \multicolumn{2}{|c|}{ Group } \\
\cline { 2 - 3 } & Control & Experimental \\
\hline Mass, g & $1418,3 \pm 10,4$ & $1543,1 \pm 10,9$ \\
\hline Absolute gain, $\mathrm{g}$ & 402,7 & 512,1 \\
\hline Average daily gain, $\mathrm{g}$ & 2,68 & 3,41 \\
\hline Average daily growth rate, $\%$ & 0,23 & 0,27 \\
\hline Fulton's condition coefficient, $\%$ & 0,22 & 0,36 \\
\hline Survival, $\%$ & 100 & 100 \\
\hline
\end{tabular}

When the fish were fed with compound feed with the addition of the probiotic "FermKM", the highest value of the absolute increase was observed $(512.1 \mathrm{~g})$, which is $109.4 \mathrm{~g}$ higher than in the control group. Indicators of the average daily growth rate differed slightly, both in the control and in the experimental variant, and ranged within $0.23-0.27 \%$. Fulton's fatness coefficient, which characterizes the fat content in the body of fish, its 
physiological state and nutritional value, had the highest indicator in the group consuming mixed feed with the probiotic preparation Ferm-KM and was $0.36 \%$ (Fig. 3).

$$
\begin{array}{r}
0,4 \\
0,35 \\
0,3 \\
0,25 \\
0,2 \\
0,15 \\
0,1 \\
0,05 \\
0
\end{array}
$$

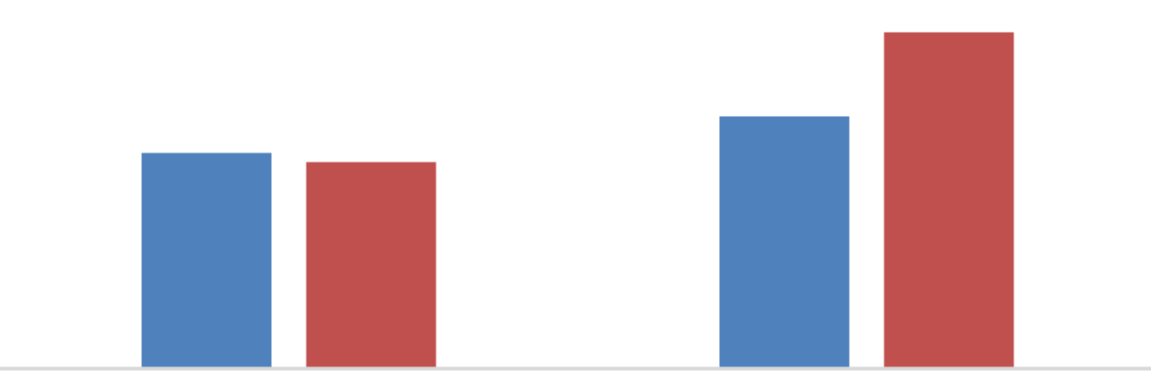

Control

Experimental

Average daily growth rate, $\%$

Fulton's condition coefficient,\%

Fig. 3. Fish-breeding and biological indicators of the cultivation of two-year-old Russian sturgeon

Thus, according to the data of biological indicators of growth, survival, we can speak of a positive effect of the immunobiological preparation based on live bacteria "Ferm-KM" when added to production feed for sturgeon fish. Its introduction into the feed formulation gives an increase in the weight gain and fatness of fish.

To assess the physiological state of fish in all variants of the experiments, an analysis of hematological parameters of two-year-old Russian sturgeon was carried out (Fig. 4).

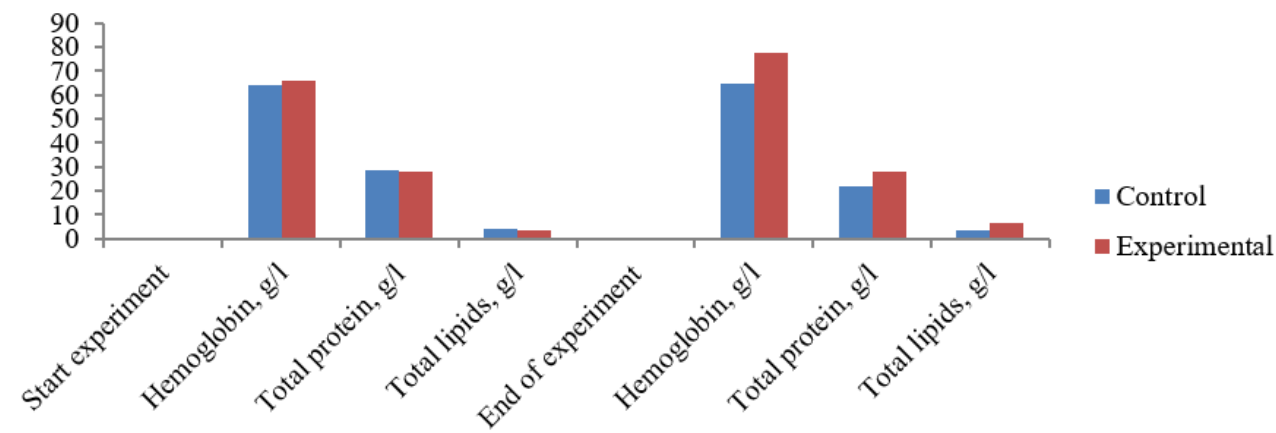

Fig. 4. Physiological and biochemical parameters of the blood of two-year-old Russian sturgeon

The concentration of whey protein, both in the control and in the experimental variants, fluctuated within the lower limit of the norm typical for fish from natural reservoirs $(25-40$ $\mathrm{g} / \mathrm{l})$ [1]. Relatively low whey protein levels are often observed in juvenile sturgeon reared in hatchery conditions. Perhaps this is due to both the specifics of nutrition and the level of stress load, which is always present when keeping fish in ponds or pools. This leads to unnecessary waste of such a biochemical substrate as protein, which is easily realized in the exchange process. The extra energy in this case is used to overcome stress. The presence of a stressful situation is confirmed by an increased level of cholesterol in the blood of fish, both in control and in the experiment. In experimental fish, it did not exceed $2.5 \mathrm{mmol} / \mathrm{l}$ (Fig. 5). If we consider cholesterol as a biochemical component that helps experienced fish overcome stress loads, its increased level (by 30-40\%) is quite natural. 


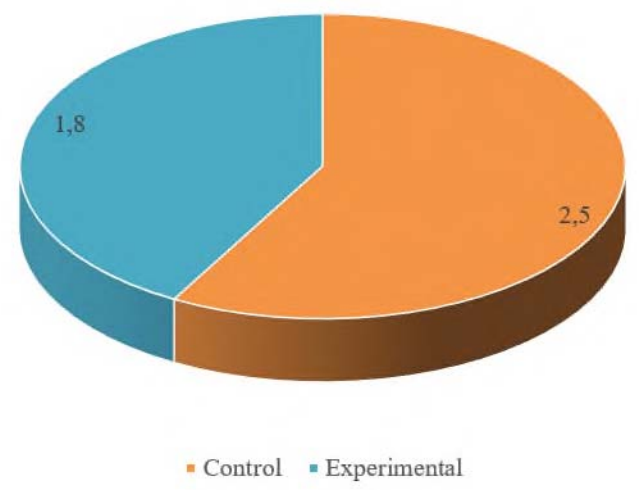

Fig. 5. The concentration of cholesterol in the blood of the Russian sturgeon

The concentration of total lipids during the study period in fish of the experimental variants slightly exceeded the norm (3-5 g/l). This allows us to conclude that the direction of fat metabolism in these fish contributed to the normal accumulation of energy resources.

The erythrocyte sedimentation rate (ESR) is of diagnostic value and in uneven-aged sturgeon fish corresponds to an average of $2.5 \mathrm{~mm} / \mathrm{h}$ [1]. In all cases, this indicator did not exceed the standard values and amounted to $2.0-2.1 \mathrm{~mm} /$ hour, which indicates the absence of inflammatory processes (Fig. 6).

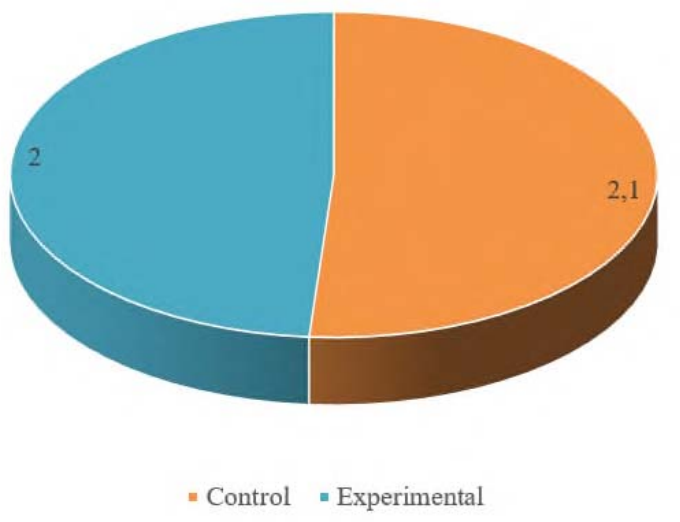

Fig. 6. ESR level in the blood of sturgeon fish

On the basis of the performed hematological studies, it can be stated that the studied immunobiological preparation based on live bacteria did not cause deviations in the state of fish health and metabolic disorders.

The addition of the Ferm-KM preparation to the production compound feed for sturgeon fish is effective and contributes to the obtaining of higher fish-biological and physiologicalbiochemical parameters.

\section{Conclusion}


In this article, she scientifically substantiated the effectiveness of the use of a modern immunobiological preparation based on live bacteria "Ferm-KM" in the composition of production feed for sturgeon fish. The positive effect of the introduction of the drug into the compound feed is the participation of beneficial bacteria in the processes of digestion and metabolism, biosynthesis, assimilation of protein and a number of other biologically active substances, ensuring the resistance of the fish organism. As a result of the use of compound feeds with a probiotic, the symbiotic microflora of the intestines of sturgeons will be corrected, which, due to its fermentation activity, will be able to synthesize many biologically active substances (organic acids, lipids, alcohols, vitamins, in particular group $\mathrm{B}$, compounds of the tetrapyrol structure). The symbiotic microflora will increase the general nonspecific resistance of the fish organism, actively participating in metabolic processes and supplying the necessary plastic substances.

\section{References}

1. N.A. Ushakova, A.I. Bastrakov, A.A. Kozlova, D.S. Pavlov, S.V. Ponomarev, Y.M. Bakaneva, Y.V. Fedorovykh, A.D. Zhandalgarova, Biology Bulletin 43(5), 450-456 (2016) doi: 10.1134/S1062359016040130

2. V.A. Zuenko, K.S. Laktionov, I.V. Pravdin, L.Z. Kravtsova, N.A. Ushakova, Journal of Ichthyology 57(1), 152-157 (2017) doi: 10.1134/S0032945217010143

3. S.S. Singh, S. De Mandal, V. Mathipi, S. Ghatak, N.S. Kumar, Biocatalysis and Agricultural Biotechnology 15, 283-290 (2018) doi: 10.1016/j.bcab.2018.07.007

4. J.A.R. Dias, H.A. Abe, N.C. Sousa, R.D.F. Silva, C.A.M. Cordeiro, G.F.E. Gomes, J.S. Ready, J.L.P. Mouriño, M.L. Martins, P.C.F. Carneiro, A.N. Maria, R.Y. Fujimoto, Aquaculture International 27(2), 463-474 (2019) doi: 10.1007/s10499-019-00339-9

5. E. Alshammari, M. Patel, M. Sachidanandan, P. Kumar, M. Adnan, Food science of animal resources 39(5), 844-861 (2019) doi: 10.5851/kosfa.2019.e57

6. L.Z. Kravtsova, D.S. Pavlov, N.A. Ushakova, V.G. Pravdin, C.A. Liman, S.V. Ponomarev, Chemical and Biochemical Technology: Materials, Processing, and Reliability, 313-319 (2014) doi: 10.1201/b17717

7. Y. Yi, J. Zha, G. Wang, Z. Zhang, F. Zhao, H.Liu, L.Yu, Fish \& Shellfish Immunology 78, 322-330 (2018) doi: 10.1016/j.fsi.2018.04.055

8. H. Cordero, F.A. Guardiola, A. Cuesta, J. Meseguer, M.T. Esteban, S.T. TapiaPaniagua, M.C. Balebona, M.T. Moriñigo, Fish \& Shellfish Immunology 45(2), 608618 (2015) doi: 10.1016/j.fsi.2015.05.010

9. M.A. Ramos, S. Batista, L.F. Pereira, M.J. Saavedra, R.O.A. Ozório, A.P. Silva, M.A. Pires, P. Rema, Animal 11(8), 1259-1269 (2017) doi: 10.1017/S1751731116002792

10. A.A. Aitkaliyeva, K.B. Isbekov, S.Z. Assylbekova, N.S. Badryzlova, S.A. Alpeisov, EurAsian Journal of BioSciences 13(1), 437-442 (2019)

11. M.L. Ruiz, M.S. Owatari, M.M. Yamashita, J.V.S. Ferrarezi, P. Garcia, L. Cardoso, M.L. Martins, J.L.P. Mouriño Tropical Animal Health and Production 52(1), 167-176 (2020) doi: 10.1007/s11250-019-02001-1

12. M. Wang, M. Yi, M. Lu, F. Gao, Z. Liu, Q. Huang, Q. Li, D. Zhu, Aquaculture Reports 17, 100309 (2020) doi: 10.1016/j.aqrep.2020.100309

13. M. Bentzon-Tilia, E.C. Sonnenschein, L. Gram, Microbial Biotechnology 9(5), 576584 (2016) 
14. I.F. Gorlov, M.I. Slozhenkina, Z.B. Komarova, I.V. Tkacheva, A.A. Mosolov, Research Journal of Pharmaceutical, Biological and Chemical Sciences 10(1), 20312035 (2019)

15. E.D. Abarike, J. Cai, Y. Lu, H. Yu, J. Jian, J. Tang, F.K.A. Kuebutornye, L. Chen, L. Jun, Fish \& Shellfish Immunology 82, 229-238 (2018) doi: 10.1016/j.fsi.2018.08.037 